The rates have remained relatively constant over the three year period. Results of post mortem examinations are presented at clinicopathology audit meetings, which are held at two weekly intervals. As the junior medical staff turnover averages six months, however, it may be that the benefits are felt in other hositals. Unlike Dr Slater, we have not found cases which should have been referred to the Coroner.

We would agree that the accurate wording of death certificates is of paramount importance for stastical reasons and the future provision of health care services. Education is certainly necessary - we cannot say, in our experience, to have definitively made inroads into this problem through audit, but will continue to emphasise the importance of this subject to the medical staff responsible for writing certificates. As the medical students also attend the meetings perhaps we shall see improvements in future years.

MM WALKER

T DUFFY

St Charles Hospital Exmoor Street

London $\mathrm{W} 10 \mathrm{6DZ}$

\section{Post mortem sampling for biochemistry} and toxicology

Dr Forrest is to be congratulated on his ACP broadsheet concerning the usefulness of post mortem sampling for biochemistry and toxicology, ${ }^{1}$ a much neglected subject. There is one assay not mentioned among the generally useless enzyme determinations and tht is the gamma glutamyl transpedise ( $\gamma \mathrm{gt})$. Over many years I have found it to be a reliable additional investigation in those dying with indications of alcohol misuse. Where there is no active liver disease, a raised $\gamma g t$ result from a peripheral blood sample gives added confidence for chronic alcoholism to be included in the cause of death

TG ASHWORTH Walsgrave Hospital,

Walsgrave, Coventry CV2 $2 D X$

1 Forrest ARW. ACP Broadsheet No. 137 Obtaining samples at post mortem examination for toxicological and biochemical analyses. F Clin Pathol 1993;46:292-6.

\section{Book reviews}

If you wish to order, or require further information regarding, the titles reviewed here, please write or telephone the BMJ Bookshop, PO Box 295, London WC1H 9JR. Tel: 071383 6244. Fax: 0713836662. Books are supplied post free in the UK and for British Forces Posted Overseas addresses. Overseas customers should add $15 \%$ for postage and packing. Payment can be made by cheque in sterling drawn on a UK bank or by credit card (Mastercard, VISA, or American Express) stating card number, expiry date, and your full name.

(The price and availability are occasionally subject to revision by the Publishers.)
Multiple Choice Questions in Pathology. 3rd edn. IL Brown. (Pp 71; soft cover £4.99.) Edward Arnold. 1993. ISBN 0-340-55164-X

This book aims to provide practice in pathology multiple choice questions (MCQs) for medical students.

An attractive feature is the good mixture of question styles. This helps relieve the monotony of reading through MCQs and gives excellent practice in exam technique. There is a good breadth of subjects, neatly divided into 25 sections. I found that the explanatory comments were written concisely and in an appropriate amount of detail. The answers to the MCQs, however, are printed in bold type in a column down the middle of the page between the questions and the explanations. It is frustrating to see the MCQ answer boldly in front of you before you have a chance to cover it up. Perhaps in subsequent editions the answers could be on the following page.

This edition has occasional ambiguities, but they are relatively few. The format of the MRCPath primary exam has changed and does not include MCQs, so it seems curious that the back cover of this edition mentions its use in preparation for this exam.

This book is excellent value and I would recommend it for medical students who are preparing for pathology exams and who require practice in MCQ technique.

TP MILLARD

Measuring Alcohol Consumption. Psychosocial and Biochemical Methods. Ed RZ Litten, JP Allen. (Pp 256; \$69.50.) The Humana Press Inc. 1992. ISBN 0-89603-231-0

Measuring Alcohol Consumption is an excellent resource for all those interested, at either a research or clinical level, in alcohol use and misuse. Accurate assessments of alcohol use are vital in monitoring alcoholism treatment and prevention programmes and investigating the links between alcohol consumption and behavioural or medical problems. Ray Litten and John Allen have edited a multiauthored volume which is highly organised, cohesive, integrated and practical. It is divided into two main sections: the first dealing with psychosocial measures; and the second with biochemical measures of alcohol consumption.

The first chapter provides a good overview of self-report methods, and emphasises that verbal reports are neither valid nor invalid, but that the important issue is that certain conditions and procedures are more conducive to response accuracy and validity. The second chapter provides an excellent review of "computerized approaches to alcohol assessment", and the finding that the results of computerised testing are generally similar to those of personal or pencil-and paper interviews.

Timeline Follow-Back (TLFB) is the best psychometrically evaluated and field-tested self-reported alcohol consumption instrument to date. Chapter 3 provides a description of the methods and a thorough discussion of its validity, and appropriate applications of this and other self-report measures in various research and clinical situations. A useful appendix provides instructions for administering TLFB which can be modified for different target groups or research projects. The final chapter of the section on psychosocial measures discusses the accuracy of subject and collateral accounts of drinking behaviour.

The second section reviews many new and complex biochemical indicators of alcohol consumption. An overview divides biological markers into several types: markers of predisposition to alcoholism (trait markers); markers of chronic or acute consumption (state markers); and markers of organ damage. Blood and liver markers in the estimation of alcohol consumption, two new markers of high alcohol consumption (carbohydrate-deficient transferrin and 5-hydroxytryptophol), and the usefulness of protein acetaldehyde adducts as state markers of consumption are all discussed. The last two chapters describe non-invasive methods for the measurement of transdermal ethanol as an assessment of ethanol consumption. The transdermal dosimeter is easy to use in an outpatient setting where patients are seen on a weekly basis and has a high degree of sensitivity and specificity. A wearable, electronic ethanol sensor/ recorder, an adaption of the same electrochemical detection technology used in breathalysers, is also discribed. Unlike the dosimeter, it provides real-time rather than cumulative monitoring of alcohol use, and therefore gives accurate quantitative and temporal tracking of ethanol consumption over extended periods.

This superbly organised, thorough, and readable book is highly recommended for all those who need to assess alcohol intake.

CAROLINE C HORWATH

Diagnostic Ultrastructure of Non-neoplastic Disease. Ed JM Papadimitriou, DW Henderson, DV Spagnolo. (Pp 728; $£ 200 \cdot 00$.) Churchill Livingstone. 1992. ISBN 0-443-03464-8

The authors stated in the Preface that this volume was intended to be a single guidebook to the diagnosis of most non-neoplastic diseases encountered in diagnostic human ultrastructural pathology. It is a companion volume to the book Ultrastructural Appearances of Tumours prepared by the same authors.

This is a multiauthor work with uniformly high standards throughout, although the chapters range in the extent to which they cover aspects of the subject. As a whole the volume is best regarded as an atlas of high quality photomicrographs with a relatively brief, but extensively referenced, textual introduction to each chapter. The photomicrographs cover most of the commonly encountered entities and there is a generous selection of illustrations of the infrequent or rare lesions, but this cannot be regarded as comprehensive, given that the authors intended to cover the range of non-neoplastic diseases where electron microscopy can contribute to the diagnosis. There is a wide enough coverage, however, for the book to act as a valuable aide memoire for an ultrastructural pathologist while pondering over a difficult specimen. This approach will be of little value to the histopathologist with occasional exposure to electron microscopy 